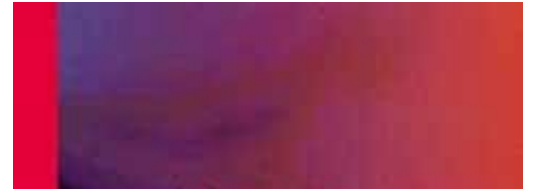

Fernando M. Reimers Editor

\section{Primary and Secondary} Education during Covid-19

Oisruptions to Educational Opportunity During a Pandemic

DPENACCESS Q Springer

Reimers, F. M. (Ed.) (2021). Primary and secondary education during Covid-19. Disruptions to Educational Opportunity During a Pandemic. 475 páginas. Springer International Publishing. ISBN: 978-3-030-81499-1

La aparición del Covid-19 dio lugar a una situación de absoluta incerteza que marcó de forma inevitable a toda una sociedad. La pandemia supuso el traslado de las realidades cotidianas del aula a los hogares de los distintos niños y niñas, así como la aplicación de nuevas formas de transmisión del conocimiento. Además, a las circunstancias personales y familiares que surgieron en cada caso, hubo que sumarle el impacto comunitario y las dificultades económicas y sociales subyacentes.

Todo ello dejó al descubierto las fragilidades presentes en los diferentes sistemas educativos, pero ofreció a las escuelas un papel protagonista a la hora de poder afrontar la fragmentación social que se había generado. Es aquí donde se presenta el complejo reto de intentar dar una respuesta educativa acorde a la complejidad escolar actual y que ve su ritmo de trabajo habitual quebrado y cambiado.

Con la idea de poder analizar esta complicada realidad, surge el libro que aquí se presenta. Se trata de un volumen editado por el profesor Fernando M. Reimers y en el que colaboran importantes profesionales del sector educativo de variadas nacionalidades y que pretende recopilar las intenciones y dificultades de la educación primaria y secundaria surgidas a corto plazo a consecuencia del Covid-19. Partiendo de una introducción muy completa y donde se define de forma clara la estructura del libro, se suceden un total de 14 capítulos que recogen el testimonio del impacto educativo que supuso la pandemia en países como Brasil, Chile, Finlandia, Japón, México, Noruega, Portugal, Rusia, Singapur, España, Sudáfrica, Reino Unido y Estados Unidos, para finalizar con un capítulo 15 que recompila de forma genérica lo acontecido y poner el broche final con un capítulo de reflexiones e implementaciones.

A lo largo de las páginas se muestra de una forma detallada, como durante este período fue necesario sustituir la enseñanza presencial y en persona, por otras alternativas que permitieran continuar el proceso educativo, generando grandes variaciones en lo concerniente a su efectividad y posibilidades de acceso.

El libro hace un atento recorrido por distintas gráficas y porcentajes que permiten adentrarse de una forma clara en el impacto de la pandemia, considerando las diferencias sociales existentes en los distintos países, sus resultados académicos en algunas áreas, el impacto emocional y psicológico, el acceso a recursos digitales y la dificultad para utilizar ciertos servicios que solían ser ofrecidos por los centros educativos. 
La pandemia ha dejado en evidencia la falta de espacios de estudio adecuado para muchos estudiantes, así como las dificultades para acceder a internet. Esto ha sido muy dispar y ha generado un crecimiento desigual a la vez que fomentado la exclusión social. El libro recoge como el problema de la brecha digital ha sido notable, lo que nos hace nuevamente repensar la educación en términos de igualdad, ya que aunque continuamente sea un concepto de uso ampliamente extendido, esta no es siempre una realidad existente. A todo ello hay que añadirle las dificultades de quienes presentan algún tipo de necesidad educativa o incluso diversidad funcional, siendo un reto doblemente complejo el que debía abordarse. En contrapartida, sin embargo, es relevante indicar que, en algunos lugares, esta situación excepcional ha contribuido a una adquisición acelerada de competencias digitales por parte del profesorado y para algunos estudiantes ha sido una oportunidad de aprendizaje y desarrollo de nuevas habilidades.

El libro se completa, a su vez, con la narración de cuáles han sido las estrategias adoptadas para intentar mitigar los efectos. Tal es el caso de algunos países como México y Costa Rica, que ofrecieron contenidos educativos por televisión, radio, facilitando material de trabajo, etc. o Kenia, que optó por suspender el curso escolar completo y retomarlo cuando las circunstancias lo permitieron o Chile y Brasil que emplearon alternativas de comunicación con las familias utilizando redes sociales y contacto telefónico, entre otros. Por el contrario, otros países como Finlandia o Noruega, presentaban un punto de partida más aventajado y una mejor posibilidad de acceso a las nuevas tecnologías.

Por otro lado, se recogen algunos argumentos críticos sobre el papel ejercido por parte de los diferentes gobiernos sobre las prioridades económicas o sanitarias abordadas, así como se hace mención a las variaciones existentes en ocasiones entre sistemas de escolarización público o privado, zonas rurales o urbanas, etc. También se recoge la gran diferencia existente entre los estudiantes pertenecientes a comunidades más ricas y más pobres en algunos lugares, estimando que en ciertos países puede incluso casi apreciarse una diferencia de un curso escolar completo, acrecentando así la brecha desigualitaria que ya de por si es protagonista en muchos países, evocando con ello al lector a una muy necesaria reflexión al respecto.

Este libro permite conocer la capacidad de las escuelas y los distintos sistemas educativos a la hora de dar respuesta a situaciones tan complejas como la vivida. Asimismo, nos agasaja con la presentación de posibles respuestas productivas que permita paliar estas consecuencias, así como plantear nuevos retos que impidan las brechas existentes y dar forma adecuada a unos sistemas educativos que, ya de por si, se corresponden a realidades difusas, cambiantes y complejas. Los resultados son presentados de forma clara y concisa mediante el análisis de diferentes estudios, así como a través de entrevistas a profesorado, estudiantes y funcionarios de gobierno; revisión legislativa, presentación de resultados de estudios, informes y documentos oficiales, cuestionarios a familias, etc.

Esta lectura no deja indiferente y pretende mostrar de una forma accesible cuál ha sido el balance del impacto educativo mediante el análisis de diferentes datos que ponen en evidencia un claro retroceso en la adquisición de aprendizajes del estudiantado, siendo estos efectos, por supuesto, heterogéneos y dispares. 
Se trata de un libro digno de elogio y felicitación, cuyos párrafos nos ofrecen de manera sencilla y de fácil lectura, las herramientas necesarias para poder comprender de una forma académica y científica la difícil situación que se ha atravesado y el impacto inmediato que ha supuesto. Por ello, este ejemplar se torna en un instrumento de necesaria lectura si lo que se pretende es ofrecer una enseñanza de calidad basada en las preocupaciones reales y sociales de una comunidad educativa con diferencias, pero que debe ser tratada y concebida desde la perspectiva de la igualdad de oportunidades.

El libro finaliza con la propuesta de retos educativos futuros y el apremio de situar la educación como una clara prioridad para poder dar respuesta a las dificultades de aprendizaje acaecidas y suavizar el probable aumento de la desigualdad social resultante. Se plasman algunas conclusiones comparativas en torno a qué tipo de enseñanza (presencial o telemática) proporciona mejores resultados y cómo se debería hacer para aplicarse en diferentes contextos, percibiendo incluso la necesidad de plantear ciertas medidas compensatorias.

En definitiva, este tomo se antoja como una invitación a la reflexión y el análisis de una realidad que pone en valor a los centros educativos no como meros transmisores de conocimientos, sino como el ingrediente esencial necesario para la existencia de una sociedad inclusiva, justa e igualitaria.

Laura García Docampo Universidade de Santiago de Compostela (USC), España 